the most ecologically important areas remain out of reach.

Moreover, in a study published last month, marine scientists Callum Roberts, Bethan O'Leary and their colleagues at the University of York, UK, conclude that the $10 \%$ target is much too low. On the basis of a review of 144 studies that assessed the adequacy of the UN target, they estimate that more than $30 \%$ of the ocean must be protected to achieve goals such as protecting biodiversity and minimizing the risk that fish populations will collapse (B. C. O'Leary et al. Conserv. Lett. http:// doi.org/bdxw; 2016). But it would be near impossible to set aside this much-larger portion without being able to create MPAs in the high seas, notes Roberts. "These negotiations over the next two years are going to be vitally important," he says.

\section{BROAD APPROACH}

Others say that MPAs aren't necessarily the best way to protect the oceans, because they can lead to problems such as overfishing in non-protected areas. Rather than setting aside large areas for protection, a better approach would be to manage activities properly across the ocean, says oceanographer James Cowan
Bioprospecting is on the rise in the oceans, particularly in the high seas, says Glen Wright, a marinepolicy researcher at the Institute for Sustainable Development and International Relations in Paris.

The G77 group of developing nations argues that genetic resources from the high seas are part of the 'common heritage of mankind', so any profits from them should be shared among all nations. Other groups, including the European Union would rather avoid such a formal status, says Wright, at Louisiana State University in Baton Rouge. Another issue being discussed during the negotiations is how to govern the search for genetic resources - plants and animals that could yield products such as drugs or cosmetics. and focus instead on a practical mechanism for sharing the benefits. But at this stage, say Wright and Wilson, it is unclear what rules might be brought in, and what mechanisms might be used to enforce them.

\section{CORRECTIONS}

In the News story 'Clash over killer-whale captivity' (Nature 531, 426-427; 2016), we erroneously referred to Jeffrey Ventre as a veterinary surgeon. He is, in fact, a physician. And in the story 'Scientists say "no" to UK exit from Europe in Nature poll' (Nature 531, 559; 2016), the labels numbered 2 and 4 in the graphic "What impact would a UK exit from the EU have on UK science?' were the wrong way round. The opening paragraph also potentially implied that the poll was more representative of scientists in the UK and greater EU than perhaps was warranted. 